\title{
Electrical Network Capacity Support from Demand Side Response: Techno-Economic Assessment of Potential Business Cases for Commercial and Residential End-Users
}

Eduardo A. Martínez Ceseña*, Nicholas Good and Pierluigi Mancarella School of Electrical \& Electronic Engineering, The University of Manchester, M13 9PL, Manchester, UK *Eduardo.MartinezCesena@Manchester.ac.uk, +44 (0) 1613068721

\section{Abstract}

Demand Side Response (DSR) is currently recognised for its potential to offer a wide variety of services to the electricity sector, which can be economically attractive for large actors such as energy retailers, Transmission System Operators (TSOs), Distribution Network Operators (DNOs), and so forth. However, little research has been as yet directed to the quantification of the benefits from these services from the perspective of small (below $100 \mathrm{~kW}$ ) commercial and residential end-users, which may not be incentivised to provide DSR under current (and emerging) market and regulatory contexts. Amongst others, gaps exist in suitable models and studies to quantify potential business cases for small customers willing to make their demand "active" considering at the same time the technical and physical characteristics of both the power system and of demand itself, as well as the economic conditions of the power market. In addition, while most existing analyses have been devoted to assess potential benefits from DSR in the retail energy market, little research has addressed network capacity support to network operators. On these premises, this paper presents comprehensive techno-economic methodologies for the quantification of three different DSR services based on the provision of network capacity to both transmission and distribution levels from small end-users' active demand. Case study results applied to a UK commercial context indicate that, if the appropriate regulatory framework is put in place, capacity support services can result into potentially attractive business cases for DSR from both the power system and small end-user perspectives. 
Highlights:

- We present three business cases for DSR from domestic and commercial end-users

- A comprehensive techno-economic methodology is proposed for the quantification of each DSR business cases

- The regulatory implications associated with each business case are discussed

Keywords: Active demand, Demand response, Demand side response, Business cases, Network investment deferral, Smart grid

\section{Abbreviations:}

ADDRESS

Active Distribution network with full integration of Demand and distributed energy

RESourceS

DCC Demand Chargeable Capacity

DNO Distribution Network Operator

DSR Demand Side Response

EHV Extra High Voltage

$\mathrm{HH} \quad$ Half Hourly

MIC Maximum Import Capacity

TSO Transmission System Operator

TNUoS Transmission Network Use of System 


\section{INTRODUCTION}

Demand Side Response (DSR) is deemed a potentially economical and efficient means to tackle emerging challenges in the power sector brought about by environmental concerns and the ever growing global dependence on electricity, among other factors. As a result, a large body of research has focused on analysing and quantifying the different benefits associated with DSR (e.g., energy consumption and peak demand reductions, reserve capacity, improved network operation and investments, and so forth (Bradley et al., 2013; Strbac, 2008; Strbac et al., 2010)). The outcomes of this research are encouraging, as DSR is expected to provide significant economic benefits to the power sector at the system level, and are driving investments in DSR enabling technologies (e.g., the smart meters rollout in the UK (Ofgem, 2014a)). Furthermore, new policies and regulatory arrangements are emerging with the aim of facilitating an efficient use of DSR, protecting the interests of all end-users, and guaranteeing that the active end-users providing DSR receive adequate incentives (e.g., the smarter markets programme in the UK (Ofgem, 2014b)). However, in order to fully achieve the benefits from DSR, it will be critical to secure the participation of small commercial and residential end-users (with contracted power below $100 \mathrm{~kW}$ ) in DSR programmes, as small end-users can comprise a significant portion of demand (e.g., 36\% in average and more than 45\% during peak times in the UK (DECC, 2013; SINTEF, 2003). This is a fundamental challenge, as it is still unclear if there is a business case for DSR for small end-users, as the aggregated benefits that are highlighted at a system level might be too low to justify investments in DSR enabling infrastructure (e.g., smart meters and devices, automation, and so forth).

Under current (and emerging) market and regulatory conditions, DSR is typically considered for provision of energy services (e.g., balancing, peak reductions and so forth), which may not offer sufficient economic incentives to small end-users to provide DSR, even if called on a regular basis (e.g., once per day) (Bradley et al., 2013; Gottwalt et al., 2011; Prüggler, 2013; Torriti, 2012). In this respect, little 
research has focused on actual quantification of potential benefits under existing (or emerging) market structures with the objective of developing specific business cases, particularly from the perspective of small end-users. In addition, research in this area tends to disregard the techno-economic effects associated with DSR such as impacts on the power system associated with, for instance, energy payback (determined by the need for resuming the service interrupted due to DSR action), energy imbalances (created in the retail market due to the DSR actuation), and so forth. Finally, while many DSR studies involving exposure of small end-users to price signals have dealt with energy markets (for instance, day ahead markets) (Gottwalt et al., 2011; Prüggler, 2013; Torriti, 2012), there is a lack of understanding and quantitative assessment of the potential to provide capacity support services to transmission and distribution networks and developing suitable business cases for customers and intermediate market agents such as aggregators.

In the light of this, further research on the quantification of the potential benefits and costs associated with DSR based services from small end-users is needed to understand whether or not there are business cases for DSR under current (and emerging) market frameworks, as well as to identify the factors that drive or discourage the business cases and which should be addressed in emerging policies and regulatory frameworks. Based on this, this paper presents some of the research findings of the "ADDRESS" (“Active Distribution network with full integration of Demand and distributed energy RESourceS") project, co-funded by the European Commission under the $7^{\text {th }}$ Framework Programme. The aim of the project was to enable active participation of small and commercial consumers to power system operation (the concept of active demand developed in the ADDRESS project is intended here to be interchangeable with DSR). In this context, this work presents the techno-economic methodologies used to quantify benefits from three potential DSR services based on the provision of transmission and distribution network capacity (capacity services) from small commercial and residential end-users, namely:

1. Avoidance of transmission level capacity charges for electricity retailers; 
2. Avoidance of charges between interconnected distribution network operators (DNOs);

3. Avoidance or deferment of system reinforcement costs for DNOs.

The methodologies were developed for the assessment of capacity based DSR services and to model the effects of this active demand on the physical electricity system and the electricity market. The capacitybased services (normally neglected in the literature, at least from the point of view of actual quantitative assessment) were chosen for the potential high value and low call frequency associated with the provision of network capacity, which are desirable characteristics from the perspective of small end-users who might provide the DSR services. This is a fundamental contribution with respect to previous studies that have focused on energy services that might have to be called upon even several times a day, for instance to respond to real time pricing mechanisms (see for instance (Gottwalt et al., 2011; Prüggler, 2013; Torriti, 2012)). As mentioned above, particular emphasis was placed on modelling relevant techno-economic effects related to DSR, namely, the (i) imbalances that DSR can introduce into the electricity market (i.e., electricity consumed by end-users that provide DSR may differ from the energy that retailers have to buy in advance in the electricity market); (ii) payback of the electricity that is curtailed due to DSR (e.g., electricity that is curtailed by postponing some activities such as laundry would be "paid back" at a later period to resume the service); and (iii) potential impacts of DSR on the operational limits of the electricity grid (e.g., thermal and voltage constraints). By addressing capacity services and explicitly modelling the technical and economic aspects of DSR, the methodologies are meant to facilitate a better understanding of potential and realistic business cases for DSR, which can be used to inform policy makers and regulators.

This paper is organized as follows. In Section 2, a general overview of DSR is provided, with particular focus being placed on existing DSR programme types and the payback and imbalance effects associated with DSR. In Section 3, the capacity based DSR business cases explored in this paper are described in detail, while Section 4 and Section 5 present the techno-economic methodologies used to 
assess these business cases and relevant numerical results, respectively. In Section 6, the main conclusions and associated policy implications of this research are presented.

\section{DEMAND SIDE RESPONSE}

DSR can be defined as an intentional change relative to the normal demand profile of end-users made in response to specific signals, price fluctuations, and so forth (Albadi and El-Saadany, 2008). The signals and associated DSR actions (e.g., reduce or increase energy consumption) are normally specified in DSR programmes which use available policies, market mechanisms, and incentives to deliver benefits to the power sector by providing services to the network or particular actors (e.g., DNOs, TSOs, energy suppliers, market operators, renewable generators, and so on). Nevertheless, calling DSR may also result in other effects related to payback effects and electricity market balancing, which might not be beneficial. It is thus critical to understand both the rationale of specific DSR programmes and all associated effects of DSR in order to properly model and quantify potential business cases.

\subsection{Demand response programmes}

A DSR programme is an agreement formulated under existing regulatory frameworks that stipulates the characteristics of a DSR service. That is, the specific signals that will be sent to end-users, expected DSR actions, incentives and penalties associated respectively to the provision or failure to provide proper DSR actions, type and amount of end-users that can provide the service, and so forth. Generally speaking, the DSR programmes can be classified based on the manner by which signals are sent to end-users, namely, as incentive-based programmes and price-based programmes (Tan and Kirschen, 2007; Torriti et al., 2010). 
In an incentive-based programme, DSR is triggered via signals sent directly to end-users. The signals might be sent directly to the devices that provide the service (i.e., direct load control); or may be sent to end-users which have the option to disregard the signal (foregoing economic benefits or being penalised). In a price-based program, DSR is incentivised by exposing end-users to varying electricity prices such as time of use tariffs, critical peak pricing, critical peak rebates and real time prices among others (see for instance (Mancarella and Chicco, 2013)).

It can be deduced that incentive-based DSR programmes may enable reliable and fast reacting active demand services. This could allow end-users to provide ancillary services to the power system and underlying actors (e.g., reserve, balancing, voltage control, and so forth), but may result in high costs for enabling infrastructure, particularly whenever bespoke communications and automation infrastructure are needed. Price-based DSR programmes, on the other hand, may be more attractive for incentivising energy efficiency and managing peak demand, as end-users can be made aware of their electricity consumption behaviour and incentivised to minimise energy consumption during peak periods. However, the reliability and consistency of underlying DSR services is arguable due to the uncertain nature of end-users (for further discussion see (Gyamfi et al., 2013; Darby and McKenna, 2012)) and the costs of enabling infrastructure can be high too, especially when real time pricing is implemented (this would require investments in smart meters and automation, among other devices, if these are not already available).

The DSR programme is typically implemented by a DSR provider, which in this work (and in the ADDRESS project) is assumed to be an actor that takes both the role of energy retailer and aggregator (Belhomme et al., 2009). This would allow the DSR provider to use various types of DSR programmes, as it would be in the position to offer end-users different types of incentives. In addition, the aggregatorretailer could also take into account the effect of the provision of active demand services on its position in the energy market (DSR provision would affect the energy to be bought in the market by the supplier or other balancing responsible party at different times, as better discussed below). 


\subsection{Payback and imbalance effects}

Whenever active demand is called to respond, it is likely to result in effects other than those stipulated in the DSR programme. More specifically, by providing DSR, an end-user might be shifting its entire demand (or parts of it) to or from different periods (payback effect) and introducing imbalances to the electricity market. An example of the payback effect can be seen in Figure 1.

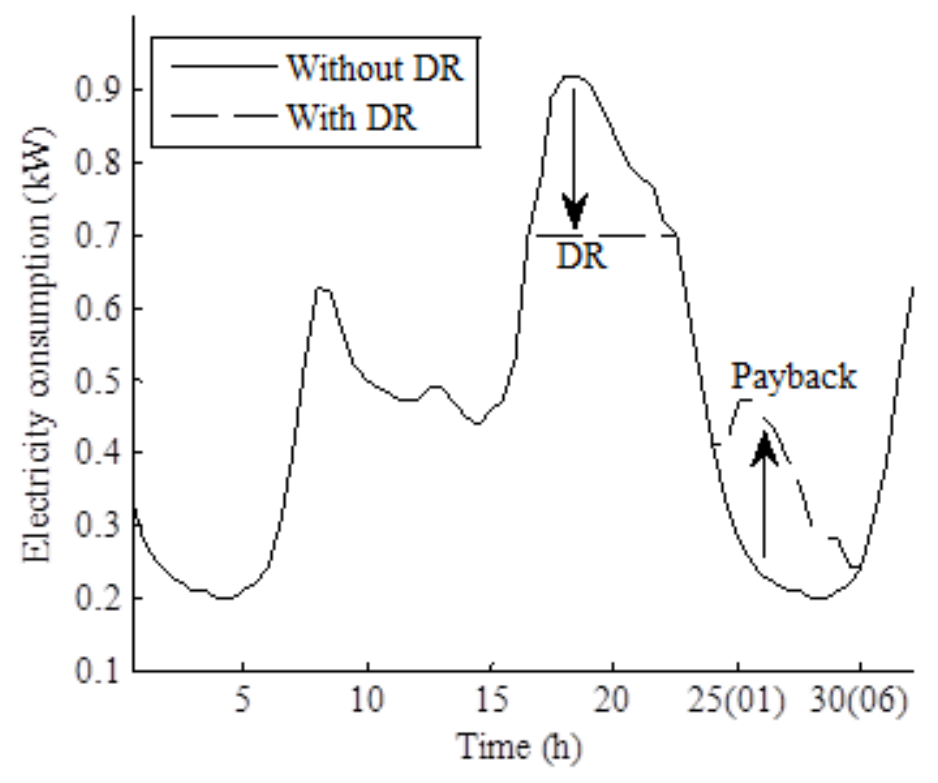

Figure 1: Example of the payback effect introduced by DSR

As shown in the figure, when DSR is called for the reduction of peak demand, some of the energy that is curtailed may be paid back at a later period. This may occur if end-users respond by depleting some energy storage (e.g., available in the building fabric by adjusting heating settings) or by deferring tasks that may have to be paid back afterwards (e.g., shifting the washing of clothes or dishes). The magnitude of the payback may be lower than the changed demand (e.g., if end-users mostly deplete thermal energy storage in building fabric, whereby in the meantime there is also partial loss of comfort), as high as the demand that 
was curtailed (e.g., if end-users mainly shift activities), or higher than that (e.g., if additional energy is consumed to compensate for lost of utility or in the presence of storage devices with losses). The time when payback occurs may be soon after DSR is provided, which could potentially create a new (and even higher) demand peak, or far from when DSR was deployed, which would allow the payback energy to be moved to off-peak periods. In this respect, it also needs to be highlighted that when looking at aggregated effects from the point of view of the aggregator and of the equivalent DSR service provided to the system, in principle it could be possible to schedule the response of specific devices so as to minimise the aggregated payback effect, also depending on the flexibility of each specific devise and user.

Demand variations caused by both DSR and the payback effect can imbalance the position of the end-user in the energy market, thus exposing the end-user (or the balancing responsible actor that represents it in the market (e.g., the retailer)) to the imbalance settlement process (Elexon, 2013a). As a side effect of the DSR action, the balancing responsible actor may incur economic losses (e.g., if a high volume of power is paid back during peak time) or accrue benefits (e.g., if payback is negligible and/or occurs during off-peak time when prices are low) from DSR.

\section{BUSINESS CASES FOR CAPACITY BASED DEMAND RESPONSE SERVICES}

The characteristics of potential DSR services and related side effects (e.g., payback and imbalances) should be properly quantified in the context of the physical electricity grid, existing (or proposed) market frameworks, and from the perspective of different actors (e.g., end-users, DNOs, TSOs, and so forth). The results would be prospective business cases for DSR, which would emphasize how the different actors involved directly or indirectly with the DSR services may accrue benefits and incur costs and, ultimately, demonstrate whether or not there is a business case for DSR at the small commercial and residential level. 
In fact, the lack of proper business models can be considered as one of the main challenges for the deployment of DSR (Giordano and Fulli, 2012; Oren, 2013).

This section presents three DSR business cases for the provision of system capacity to the transmission and distribution networks during critical times (e.g., when demand approaches the yearly peak) that have been quantified as part of the ADDRESS project. As mentioned in section 1, these capacity services were chosen over more typical energy services (for instance to respond to hourly pricing) after analysing the characteristics of both types of services. It is worth noting that the business case for DSR from energy services can be attractive under certain conditions such as the existence of time-based electricity pricing schemes with price differentials sufficient to provide economic incentives for end-users, DSR providers, and other actors, among others (De Ridder et al., 2011; Doostizadeh and Ghasemi, 2012). However, even under the aforementioned conditions, frequent DSR calls would be needed (even several times a day, as also confirmed by the results in the ADDRESS project (Linares, 2013)), which might put off the end-user. To illustrate this, consider for instance a typical time-of-use tariff in the UK with a cost of $£ 0.15 / \mathrm{kWh}$ during the day time. If small end-users are capable and willing to curtail $1 \mathrm{kWh}$ every day, they would save $£ 54.75$ per year (365 days $x 1 \mathrm{kWh} \times £ 0.15 / \mathrm{kWh}$ ). This value would likely be lower once the payback effect, market imbalances, DSR provider fees, and other factors are considered. Conversely, capacity based services could likely have a lower call frequency (only when the demand approaches network capacity relevant to the specific service to be provided). Whether or not and under what conditions economic incentives for small end-users to provide such services may be attractive will be explored in the sequel with reference to three specific services available or potentially available in the UK. 


\subsection{Business Case 1: Avoidance of transmission capacity charges}

In the UK, Transmission Network Use of System (TNUoS) charges are levied on retailers (and generators) by the TSO to pay for the maintenance, operation, and development of the transmission network. The retailer pays two TNUoS charges; one for its Half Hourly (HH) metered end-users and one for its non-HH metered end-users. The TNUoS charges for non-HH end-users are determined based on the estimated consumption of the end-users between 16:00h and 19:00h. The TNUoS charges for HH end-users are determined via a tariff levied on the end-users' average consumption over three specified settlement periods in the year called "TRIADs". More specifically, TRIADs are the three (half hourly) settlement periods of maximum demand during the year separated by at least 10 clear days (Flextricity, 2013; GDF SUEZ, 2013; Npower, 2013).

Minimisation of consumption over the TRIADs (so-called "TRIAD management") can lead to lower TNUoS charges for the retailer. This charging methodology also has the deliberate side result of minimising the system peak, and hence transmission network (and indirectly generation) investments, through its incentivisation of demand minimisation at peak times. In practice, TRIADs are unknown until the TRIAD season for the year (defined as November-February) is completed, as they are defined ex-post. However, TRIADs can be predicted with relatively good accuracy. Predictions (known as "TRIAD warnings") are either made in-house by electricity retailers or are provided on a commercial basis by specialists (Flextricity, 2013; GDF SUEZ, 2013; Npower, 2013). The lead time of TRIAD warnings vary (from day-ahead to around 8 hours ahead), as do the number of warnings (usually around 15 to 20 per year). Thus, given $\mathrm{HH}$ metering for small commercial and residential end-users (it is assumed that all residential customers with active demand would also be half-hourly metered as enabled for instance by smart meters' rollout), there could be a business case under the present regulatory framework for an active demand aggregator to offer a service to the TSO by providing capacity services in response to TRIAD 
warnings. As the capacity delivered upon the service call is not specified and the service is rather aimed at minimising exposure to TNUoS charges, this DSR service could for instance be implemented via an incentive-based or critical peak pricing/rebate DSR programme.

\subsection{Business Case 2: Avoidance of charges between neighbouring DNOs}

In the UK, neighbouring DNOs can exchange power via interconnections (normally at the Extra High Voltage (EHV) levels, i.e., more than $22 \mathrm{kV}$ and up to $132 \mathrm{kV}$ ), in which case they treat each other as EHV end-users and are charged for their contracted capacity. In this context, DNOs could reduce their contracted capacity or avoid capacity charges by using DSR services for the reduction of their peak demand.

In accordance with the EHV distribution charging methodology in place in the UK (ENA, 2011) (taken here as a specific example, while similar approaches are likely to be adoptable in other countries, based on the same principles), interconnected DNOs are charged based on (i) their "super red period" energy consumption; (ii) a fixed charge; and (iii) their Demand Chargeable Capacity (DCC).

The "super red" fee is applied to all energy (kWh) consumed between 16:00h and 19:00h on every weekday from November to February (assumed to be peak times according to the current regulation and based on typical system profiles). When the capacity service is called, demand might be shifted away from the super red rate, thus resulting in super red charge savings.

The fixed charge remains the same regardless of demand, thus it could be argued that the capacity service should not affect this charge. Nevertheless, in practice, the DNO would use the interconnection as a means to cope with peak demand, which can also be affected by DSR. In fact, if sufficient active demand were available, DSR could replace the interconnection and therefore avoid the fixed cost too. 
The capacity charge is based on the DCC represented in (1) (ENA, 2011).

$$
D C C=\operatorname{Max}\left(2 \times \sqrt{A I^{2}+R I^{2}}, \mathrm{MIC}\right)
$$

where $A I$ and $R I$ are the active and reactive components of electricity imports during a settlement period (i.e., half hour period), and MIC is the Maximum Import Capacity of the interconnection, which is agreed before interconnecting the distribution networks (this capacity can be adjusted on a yearly basis).

Normally, the DNO would pay a fixed fee for the use of an interconnection based on the MIC. However, the DNO would have to pay an "exceeded import capacity charge" and may be obliged to negotiate a higher MIC in the case that demand in its network is such that the DCC exceeds the MIC originally agreed for the interconnection. Increasing the MIC would only result in additional connection charges for the DNO whenever the neighbouring distribution network has to be reinforced to handle the new capacity of the interconnection. In this light, the interconnection can be seen as an alternative for DNOs to avoid or minimise own reinforcement costs by using existing capacity in (or reinforcing) neighbouring networks. Considering that network reinforcement cost avoidance is preferred, it is reasonable to assume that DNOs would be keen to limit the capacity of the interconnection so that only available capacity in adjacent networks is used. Accordingly, there may be a business case for active demand aggregators to offer a service to the DNO by providing capacity services to limit the MIC of the interconnection under the abovementioned regulation. Also, considering that the service calls can be forecasted with a reasonable level of accuracy because local system peaks are relatively easy to foresee (this is somehow similar to TRIAD warnings, thus it is reasonable to assume that the activation of the service could be predicted roughly a day ahead), the use of critical peak pricing/rebate as an economic incentive would be feasible. 


\subsection{Business Case 3: Avoidance or deferral of network reinforcement}

Apart from interconnecting their distribution networks, DNOs have the option to reinforce the network to cope with thermal and voltage constraints (among other constraints) as peak demand increases. Therefore, as hinted in the previous business model, DSR could be used to avoid or defer the need of network reinforcement.

Currently there is no market or regulatory propositions in the UK to price and trade such a service. Furthermore, that this business case may not be incentivised under current distribution charging regulations, which are not fully cost-reflective yet and thus do not fully internalise the benefits associated with the DSR service considered in this business case (Ofgem, 2014c, 2012). However, some DNOs are implementing pilot projects to increase network capacity and defer network reinforcements in which DSR services are contracted directly from end-users (e.g., the "Capacity to Customers" project (ENWL, 2013) in which the authors are involved) to test the technical feasibility of this option, following which suitable regulatory development is likely to happen. In accordance, it is assumed here that this service will be traded between the DSR provider and DNOs based on an agreed methodology to estimate underlying reinforcement costs avoided/deferred via DSR. As in the previous business case, particularly if the need for the service were to be foreseen in advance, DSR provision could be signalled via a critical peak pricing or rebate DSR programme, for instance.

\section{METHODOLOGY AND ASSUMPTIONS}

This section presents key assumptions for the assessment of the presented business cases. The main considerations common to all cases are discussed, followed by specific considerations for each of them. 


\subsection{DSR technical modelling}

Two models for DSR technical characteristics are considered for the evaluation of all business cases introduced above. The models characterise DSR in terms of the end-user's electricity consumption halfhourly demand profile (i.e., residential and commercial), flexibility (i.e., percentage of the total demand that can be used for DSR per call at a given time), and energy payback characteristics (how much of and when the energy curtailed during the DSR call is recovered to resume the underlying service), as summarised in Table 1 and as expanded on below.

Table 1: DSR technical models considered in this study

\begin{tabular}{ccccc}
\hline User & Peak load & \multicolumn{2}{c}{ Flexibility } & Payback \\
& & Typical & Full & \\
\hline Residential & $0.89 \mathrm{~kW}$ & $42 \%(0.37 \mathrm{~kW})$ & $100 \%(0.89 \mathrm{~kW})$ & $100 \%$ \\
Commercial & $22.15 \mathrm{~kW}$ & $31 \%(6.86 \mathrm{~kW})$ & $100 \%(22.15 \mathrm{~kW})$ & $50 \%$ \\
\hline
\end{tabular}

\subsubsection{User type and electricity consumption profiles}

The electricity consumption profiles represent the baseline demand of an end-user before DSR is deployed. Two consumption profiles were selected, corresponding to typical commercial and residential UK end-users (Elexon, 2013b). The profiles comprise $48 \mathrm{HH}$ demand points for typical weekdays, Saturdays and Sundays during the four seasons. The profiles for a typical weekday during winter are shown in Figure 2. 


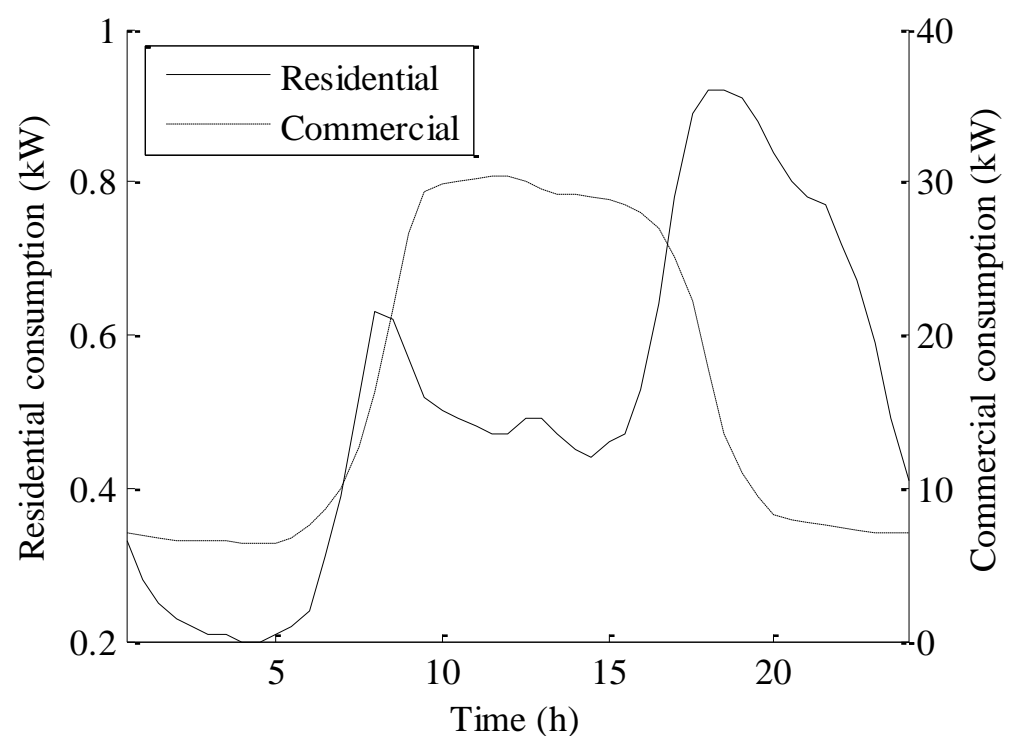

Figure 2: End-user consumption profiles.

\subsubsection{Demand flexibility}

The level of demand flexibility dictates the percentage of demand that can be curtailed at a given time in the event DSR is deployed. Two levels of flexibility were selected for each DSR model, namely, the typical level of flexibility that the average end-user in the UK is expected to have around peak times (when it is likely that capacity services will be called) and the maximum feasible level of flexibility end-users could provide by being disconnected. The latter is an extreme case considered for illustrative purposes, as it provides a theoretical maximum boundary of the economic benefits that end-users could receive from the service. However, it may be possible that, after adequate economic incentivisation, some users (particularly in the domestic sectors) might be willing to be fully disconnected if the service notice is in the region of one day so that there is enough time to reschedule activities.

For the residential end-user model, flexibility of $42 \%$ was assumed for all business cases. This is the average consumption of those appliances deemed to be flexible (e.g., washing machines, tumble dryers, dishwashers, water heaters with storage, and so forth) at 17:00h-18.00h (the settlement periods at times of 
high system stress, and hence the predominant time-band in which the capacity services would be called) according to the bottom-up electricity consumption model presented in Richardson et al. (2010). For the commercial end-user model, flexibility of $31 \%$ was assumed. This is the average proportion of consumption attributable to uses deemed to be flexible (i.e., heating, ventilation, and air conditioning as well as hot water, predominantly) across various commercial building types, according to UK HH meter data (Ofgem, 2013).

\subsubsection{Energy payback and imbalances}

As discussed previously, the costs and benefits associated with changes in energy consumption brought about by capacity service calls and payback effects were calculated considering the UK's imbalance settlement process (Elexon, 2013a). The energy payback model indicates how much of the avoided energy usage must, as a result of the service call, be consumed in periods following the service call. In all cases, payback was assumed here to occur one hour after the DSR call, based on the experience of real trials in the ADDRESS project. It is worth noticing this could in principle introduce new demand peaks that could trigger further DSR, thus increasing the frequency of the capacity services. For the residential case, an energy payback of $100 \%$ was assumed in the model. This is because the processes being considered involve either energy demand shifting (e.g., washing machines, tumble dryers, dishwashers) or energy storage which is practically lossless over a timescale of an hour (e.g., hot water storage).

For the commercial instance, levels of energy payback are difficult to model for general cases. However energy modelling work conducted on commercial properties using the EnergyPlus software tool (U.S. Department of Energy, 2013) indicated payback for space heating/cooling (which constitutes $91 \%$ of commercial flexibility) could be in the region of $50 \%$ or below (Dejvises, 2011), as heat stored in the fabric of the building is depleted during the service call and must be replenished. Thus, for the purposes of this study, an energy payback of 50\% was assumed for illustrative but realistic purposes. 
In this work, the imbalance costs are estimated with (2) and (3), which take the payback effects into consideration.

$$
\begin{aligned}
& \text { Total_Imbalance_Costs }=\sum_{t} \text { Imbalance_costs }_{t} \\
& \text { Imbalance_costs }_{t}=\text { Energy_curtailed }_{t} \times\left(\text { payback }_{t+p b} / 100 \times S B P_{t+p b}-S S P_{t}\right)
\end{aligned}
$$

where Total_Imbalance_Costs and Imbalance_costs I $_{t}$ are respectively the total imbalance costs throughout a year and during a period, Energy_curtailed ${ }_{t}$ is the energy $(\mathrm{kWh})$ curtailed during a period, payback $_{t+p b}$ is the percentage of the energy curtailed due to DSR which is paid back at a later period, $S B P$ and SSP are the electricity market balancing prices as from the UK Balancing Mechanism (i.e., "System Buy Price" and "System Sell Price" in $£ / M W h$ ) (Elexon, 2013a), and the subscripts $t$ and $t+p b$ denote the HH settlement periods when energy is curtailed and paid back, respectively.

\subsection{Peak demand reductions and energy shifting}

The capacity services have as the main aim the reduction of aggregated peak demand for a given cluster of users, and in the case of Business Cases 2 and 3 the service must guarantee that demand remains below specific targets (while for Business Case 1 the aim is to reduce demand as much as possible). The frequency with which end-users would be required to participate in DSR calls throughout a year is therefore a direct function of the peak reduction target set in the DSR programme. In order to illustrate this dependence, consider Figure 3, which shows the electricity consumption profile (scaled down to $100 \mathrm{~kW}$ for illustrative purposes) of a UK medium voltage distribution network for a day and the same profile adjusted by capacity services corresponding to maximum peak demand targets of $95 \mathrm{~kW}$ (5\% peak reduction owing to DSR) and $90 \mathrm{~kW}(10 \%$ peak reduction owing to DSR). Payback is assumed to occur one hour after the service is called, which results in additional service calls to shift the demand exceeding the threshold to off-peak times. It can be seen that, as the peak reduction target increases, demand exceeding the threshold increases and therefore DSR would have to be called more frequently (on a half hourly basis). 
This implies that the lower the peak demand reduction target, the lower the amount and frequency of DSR calls and related end-user disutility.

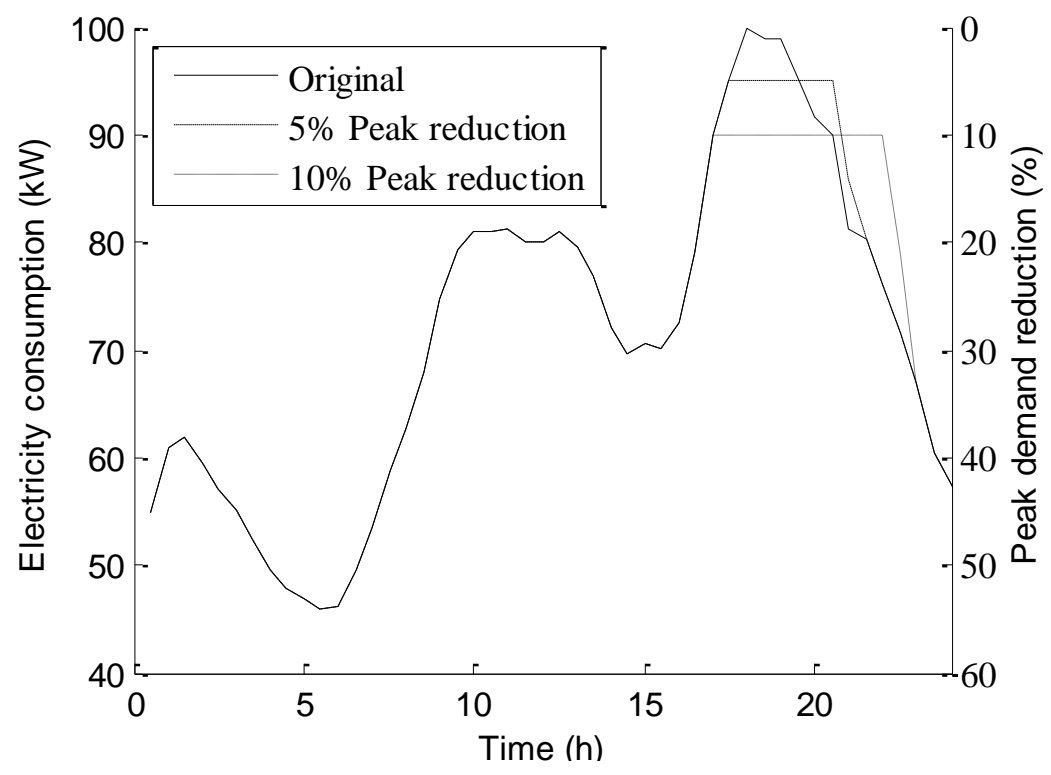

Figure 3: Example of 5\% and $10 \%$ peak demand reductions with relevant payback

\subsection{Assumption for the avoidance of transmission capacity charges (Business Case 1)}

\subsubsection{Service call logic}

TRIAD warnings are assumed to be issued on a day-ahead basis, each warning typically being for two consecutive HH periods, and no more than 15 warnings are issued per year. These assumptions are generally consistent with the practices of commercial TRIAD warning service's providers (Flextricity, 2013; GDF SUEZ, 2013; Npower, 2013).

Analysis of system load data for the 2010-11 TRIAD season was conducted to estimate the dates and times of the TRIAD warnings. The warnings were estimated using the following algorithm: 
1. For each day in the TRIAD season, a day was declared a TRIAD warning day if the maximum system demand on that day was greater than some trigger value and greater than in the 10 previous days.

2. The trigger value is altered until 15 days remained. The final trigger value used was 51.5 GW (for the sake of comparison, maximum annual peak demand in the UK is normally in the region of $55 \mathrm{GW})$.

3. The demand on the $\mathrm{HH}$ settlement period preceding and succeeding the maximum $\mathrm{HH}$ demand period on each day was calculated. The period which has the higher demand is assumed to make up the second settlement period of the TRIAD warning.

\subsubsection{Service revenue}

For this study the TNUoS charges were taken from 2010 data (National Grid, 2013a). TNUoS charges are disaggregated by 14 zones, with varying levels of charges according to the utilisation of the network in each zone. For this work a high, average and low TNUoS charges are used, relating to the maximum $(£ 26.76 / \mathrm{kW})$, average $(£ 19.83 / \mathrm{kW})$, and minimum $(£ 5.87 / \mathrm{kW})$ charges, respectively.

\subsection{Assumptions for the avoidance of charges between neighbouring DNOs (Business Case 2)}

\subsubsection{Service call logic}

The amount of service calls for this business case is determined for the baseline scenario via simulations. That is, the capacity service is triggered whenever demand (real UK HH data (National Grid, $2013 b)$ ) is within $5 \%$ of its annual maximum. Without loss of generalization, the system demand was in this case used as a proxy for the local network demand (in most cases times for system peaks and local peaks coincide) as no specific distribution network was analysed. Simulations consider the technical and 
economic effects of DSR (i.e., potential introduction of new peaks that can trigger the capacity service and increase service frequency, shift of energy to high/low price periods, imbalance settlements, and so forth).

\subsubsection{Service revenue}

The economic benefits associated with this business case are estimated as expected capacity fee savings (i.e., super red rate, fixed and import capacity charge reductions). For this purpose, example capacity fees from the "EHV distribution charging methodology" documents were reviewed (ENA, 2011) and, among these, five fees were selected to represent "typical", "pessimistic", and "optimistic" scenarios as described below and summarised in Table 2.

- Pessimistic: This scenario is based on the fee with the lowest import capacity costs and on the assumption that DSR is not enough to avoid fixed charges.

- Typical: In this scenario all fees take their average value, but the fixed charges cannot be avoided.

- Best typical: In this scenario all fees take their average value and there is sufficient DSR to also avoid fixed charges.

- Optimistic: This scenario is based on the tariff with the highest capacity fees and the assumption that DSR is not enough to avoid fixed charges.

- Best optimistic: This scenario is based on the tariff with the highest fixed fees and is sufficient DSR to also avoid fixed charges.

Table 2: Scenarios for the DNO interconnection costs reduction business case

\begin{tabular}{c|ccc}
\hline Scenario & $\begin{array}{c}\text { Super red rate } \\
\text { f/MWh }\end{array}$ & $\begin{array}{r}\text { Fixed charge } \\
\text { \&/day }\end{array}$ & $\begin{array}{c}\text { Import capacity charge } \\
\text { f/MVA/day }\end{array}$ \\
\hline Pessimistic & 0 & 48.07 & 2.80 \\
Typical & 11.23 & 14.66 & 28.7 \\
Best typical & 11.23 & 14.66 & 28.7 \\
Optimistic & 44.66 & 2.63 & 255 \\
Best optimistic & 0 & 547 & 4.2 \\
\hline
\end{tabular}




\subsection{Assumptions for the avoidance or deferral of network reinforcement (Business Case 3)}

\subsubsection{Service call logic}

As in the previous business case, the service calls are simulated based on the objective to limit maximum demand by $5 \%$ and considering the technical and economic implications of DSR.

\subsubsection{Service revenue}

Since such a service is not available yet under the current Regulation (at least in the UK), the potential revenue from the service is estimated here on the basis of the projected avoided cost of network reinforcement, which in turn is a function of the network topology, the level of reinforcement, and the timing of reinforcement, as better discussed below.

\subsubsection{Distribution network models}

In order to estimate the potential cost of reinforcement for generic cases, two test distribution networks are considered for this study, representing typical $11 \mathrm{kV}$ urban and rural systems in the UK (Grenard, 2009). More specifically, in urban networks loads tend to be grouped relatively close together (all lines are assumed to be $5 \mathrm{~km}$ long), thus reinforcements are generally mainly driven by thermal constraints. In rural networks, loads tend to be more segregated from each other (all lines are assumed to be $40 \mathrm{~km}$ long), thus reinforcements are generally likely to be driven by voltage considerations. Both networks are assumed to comprise two 17.5 MVA transformers (the second transformer is usually redundant for security considerations) connected to eight radial lines with loads uniformly distributed throughout their length, for the sake of simplicity (view Figure 4). 


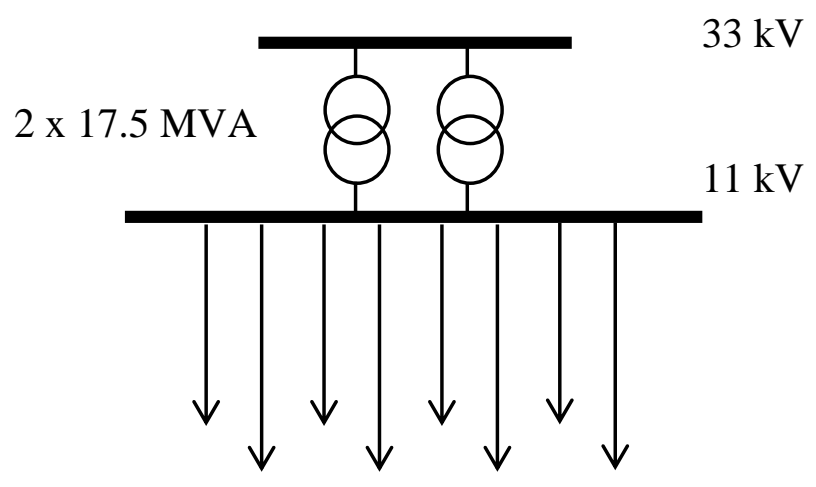

Figure 4: Typical 11kV UK test distribution network used for network reinforcement studies.

\subsubsection{Modelling cost of reinforcement and value of investment deferral}

It is assumed that network reinforcements refer to both transformer and line upgrades. Transformers are upgraded via the installation of a new 17.5MVA transformer in parallel, whereas lines are replaced with conductors with greater capacities, as from typical practices of DNOs. The data for lines and transformers were taken from (Green et al., 1999). The reinforcement costs (in £/MW/year) are estimated for different levels of demand according to typical power system techno-economic models, such as in (Cossi et al., 2012; Khodr et al., 2009). In addition, distribution network reinforcements might be either imminent or expected sometime in the future. In both cases, the implementation of capacity services can defer reinforcements or even avert them if load growth is sufficiently small (or if in the future load were to stop growing). The potential (in terms of time) of capacity services to defer reinforcements can be estimated with (7), while the impacts of deferral on the expected value of the reinforcement are expressed by (7) and (8).

$$
\begin{aligned}
& \text { Reinforcement_deferral }=\frac{\log (1 /(1-\text { Peak_demand_reduction } / 100))}{\log (1+\text { Peak_demand_growth } / 100)} \\
& \text { Discount }=\left[(1+d / 100)^{- \text {Reinforcement_time }}-(1+d / 100)^{-(\text {Reinforcenent_time+Reinforcement_deferal })}\right]
\end{aligned}
$$




$$
\text { Reinforcement_Cost_deferral }=\text { Discount } \times \text { Reinforcement_Cost }
$$

where Reinforcement_deferral is the expected time (years) that reinforcements can be delayed via the use of DSR, Peak_demand_reduction is the peak demand reduction (\%) as illustrated in Figure 3, Peak_demand_growth is the annual peak demand growth in the network (\%), Discount is a factor (\%) to adjust the reinforcement costs based on discounting and investment timing, Reinforcement_time is the time (years) when the reinforcement is initially expected (without considering active demand), $d$ is the discount rate (\%) and Reinforcement_Cost and Reinforcement_Cost_deferral are the expected discounted reinforcement costs before and after deferring reinforcements via the implementation of a DSR programme, respectively.

\section{RESULTS AND DISCUSSION}

\subsection{Capacity service call frequency}

Table 3 shows the quantification of the annual capacity service call frequency for Business Cases 2 and 3 (the call frequency for Business Case 1 is always $30 \mathrm{HH}$ periods corresponding to $15 \mathrm{~h}$ ) under different peak demand targets for the case of the UK system profile (National Grid, 2013b). This is estimated under the assumption that all available flexible demand can be represented with either the residential or the commercial DSR models (i.e., flexibility and payback characteristics), and that all endusers participate in the same amount of service calls. It can be seen that the average number of calls per end-user are lower than the expected capacity service calls. In other words, not all active customers are needed for every service call. This is reasonable considering that maximum DSR capacity (i.e., the case when all active customers are required to provide the service at the same time) is seldom needed. 
Table 3: Annual service calls per year and per end-user providing DSR

\begin{tabular}{ccccc}
\hline \multirow{2}{*}{$\begin{array}{c}\text { Peak demand } \\
\text { reduction target }\end{array}$} & \multicolumn{2}{c}{$\begin{array}{c}\text { Expected number of service calls per year } \\
\text { (HH settlement periods) }\end{array}$} & \multicolumn{2}{c}{$\begin{array}{c}\text { Average number of calls per year per end-user } \\
\text { (HH settlement periods) }\end{array}$} \\
& Residential & Commercial & Residential & Commercial \\
\hline $1 \%$ & 0.6 & 0.2 & 0.2 & 0.2 \\
$3 \%$ & 8.5 & 7.4 & 3.3 & 2 \\
$5 \%$ & 31 & 27 & 15 & 23 \\
$7 \%$ & 76 & 64 & 42 & 45 \\
$9 \%$ & 151 & 124 & 90 & \\
\hline
\end{tabular}

From the table, it can be seen that a peak reduction target of 5\% would result in roughly $30 \mathrm{HH}$ service calls per year. This is consistent with the typical 15 hours of TRIAD warnings, and hence a peak reduction of 5\% is selected in this work as a baseline for Business Cases 2 and 3 too, assuming that this corresponds to a sensible level of end-user participation.

\subsection{Comments on avoidance of transmission capacity charges (Business Case 1)}

Unlike Business Cases 2 and 3, the expected revenue per $\mathrm{kW}$ of active demand for different endusers does not vary and follows the charges of the TRIAD mechanism $(£ 26.76 / \mathrm{kW}, £ 19.83 / \mathrm{kW}$ and $£ 5.87 / \mathrm{kW}$ respectively for the high, average and low cases). Once the high, average and low charges for the active demand used to provide the service are given, the relevant value of providing this capacity service can be calculated. Table 4 thus shows the annual expected revenue for residential and commercial DSR providing typical and full flexibility in the presence of high, low, and average transmission charges. 
Table 4: Annual revenues per active end-user for Business Case 1

\begin{tabular}{ccccc}
\hline & \multicolumn{2}{c}{ Residential } & \multicolumn{2}{c}{ Commercial } \\
Charges level & \multicolumn{2}{c}{ (£/year) } & & \multicolumn{2}{c}{ (£/year $)$} \\
\hline & Typical & Full & Typical & Full \\
& flexibility & flexibility & flexibility & flexibility \\
Low & 2.3 & 5.5 & 49 & 158 \\
Average & 7.5 & 18 & 145 & 469 \\
High & 10 & 24 & 193 & 621 \\
\hline
\end{tabular}

Revenues for commercial customers substantially outweigh those for residential customers, due to the larger load of commercial customers. Another key observation is that the revenue increase for commercial end-users from providing full as opposed to typical flexibility is $322 \%$, higher than the equivalent figure for residential end-users $(240 \%)$. This is due to the comparative values of typical flexibility for residential and commercial customers ( $42 \%$ and $31 \%$ respectively), which results in greater headroom for increasing revenue for commercial customers who could be able to raise their flexibility level.

\subsection{Comments on avoidance of charges between neighbouring DNOs (Business Case 2)}

Table 5 shows the annual expected economic benefits per $k W$ of $D S R$ based on the residential and commercial DSR models in the baseline scenario (i.e., 5\% peak demand reduction) and the average enduser calls (as described in Section 5.1), whereas Table 6 shows the expected revenue per HH call associated with the participation of active end-users. The latter information could be used to estimate the expected revenues for end-users that participate in the service more or less frequently than the average. For example, the revenues associated with an end-user that participates in every service call would be $105 \%$ (residential) or $184 \%$ (commercial) higher than those of end-users participating in the average amount of calls. 
Ultimately, the participation of active end-user in the service (and related benefits) will have to be agreed with the DSR provider before implementing the service, and the above estimates can be very helpful to set up relevant contracts.

Table 5: Expected annual revenue per $\mathrm{kW}$ of DSR for Business Case 2

\begin{tabular}{ccc}
\hline & $\begin{array}{c}\text { Residential } \\
(\mathfrak{f} / \mathrm{kW} / \text { year })\end{array}$ & $\begin{array}{c}\text { Commercial } \\
(\mathfrak{f} / \mathrm{kW} / \text { year })\end{array}$ \\
\hline Pessimistic & 0.9 & 1.1 \\
Typical & 10 & 11 \\
Best typical & 17 & 17 \\
Optimistic & 93 & 94 \\
Best optimistic & 229 & 230 \\
\hline
\end{tabular}

Table 6: Expected revenue per $\mathrm{kW}$ of DSR per HH service call participation for Business Case 2

\begin{tabular}{lcl}
\hline & $\begin{array}{l}\text { Residential } \\
(\mathfrak{f} / \mathrm{kW} / \mathrm{call})\end{array}$ & $\begin{array}{l}\text { Commercial } \\
(\mathfrak{f} / \mathrm{kW} / \text { call })\end{array}$ \\
\hline Pessimistic & 0.1 & 0.1 \\
Typical & 0.7 & 1.1 \\
Best typical & 1.1 & 3.8 \\
Optimistic & 6 & 10 \\
Best optimistic & 15 & 24 \\
\hline
\end{tabular}

Table 7 shows the expected annual economic benefits that end-users providing DSR could receive by providing their typical and fully flexible active demand and based on the average participation per enduser. 
Table 7: Annual revenues per active end-user for Business Case 2

\begin{tabular}{ccccc}
\hline & \multicolumn{2}{c}{ Residential } & \multicolumn{2}{c}{ Commercial } \\
& Typical & Full & Typical & Full \\
& $(£ /$ year $)$ & $(£ /$ year $)$ & $(£ /$ year $)$ & $(£ /$ year $)$ \\
\hline Pessimistic & 0.3 & 0.8 & 8.0 & 26 \\
Typical & 3.9 & 9.2 & 73 & 235 \\
Best typical & 6.1 & 15 & 115 & 371 \\
Optimistic & 35 & 83 & 642 & 2074 \\
Best optimistic & 85 & 204 & 1577 & 5094 \\
\hline
\end{tabular}

\subsection{Comments on avoidance or deferment of network reinforcement (Business Case 3)}

In order to determine plausible reinforcement costs and thus economic values for this business case, several typical demand growth scenarios and planning horizons for the UK test systems were set. These factors determine the demand level that the reinforcement would be designed to cope with (and are used as inputs for the mathematical programming approach mentioned in Section 4.5). Accordingly, demand growth is assumed to be $1 \%, 2 \%$, or $3 \%$, while the planning horizon is set to 10 years, 20 years or 30 years. This process results in 18 scenarios (see Table 8). However, for the sake of simplicity, only the scenarios corresponding to the minimum, average, and maximum reinforcement costs are considered (see Table 9).

Table 8: Example of potential expected network reinforcement annuitized costs for urban and rural networks for different load growths

\begin{tabular}{cccccccc}
\hline Horizon & \multicolumn{2}{c}{ Urban (£/MW/year) } & \multicolumn{3}{c}{ Rural (£/MW/year) } \\
(years) & $1 \%$ & $2 \%$ & $3 \%$ & $1 \%$ & $2 \%$ & $3 \%$ \\
& growth & growth & growth & growth & growth & growth \\
\hline 10 & 522 & 860 & 1238 & 837 & 1680 & 2511 \\
20 & 860 & 1716 & 2863 & 1685 & 3466 & 5498 \\
30 & 1256 & 2868 & 4843 & 2570 & 5607 & 9160 \\
\hline
\end{tabular}


Table 9: Minimum, Average, and Maximum reinforcement cost scenarios

\begin{tabular}{lccc}
\hline & Minimum & Average & Maximum \\
\hline Urban (£/MW/year) & 522 & 1716 & 4843 \\
Rural (£/MW/year) & 837 & 3466 & 9160 \\
\hline
\end{tabular}

Table 10 shows the expected annual revenue per $\mathrm{kW}$ of DSR based on the baseline scenario (i.e., 5\% demand peak reduction) and average calls per end-user, whereas Table 11 shows the expected revenues associated with active demand per HH service call.

Table 10: Expected annual revenue per $\mathrm{kW}$ of DSR for Business Case 3

\begin{tabular}{ccc}
\hline & $\begin{array}{c}\text { Residential } \\
(\mathfrak{f} / \mathrm{kW} / \text { year })\end{array}$ & $\begin{array}{c}\text { Commercial } \\
(\mathfrak{f} / \mathrm{kW} / \text { year })\end{array}$ \\
\hline Urban minimum & 10 & 11 \\
Urban average & 34 & 34 \\
Urban maximum & 97 & 97 \\
Rural minimum & 17 & 17 \\
Rural average & 69 & 69 \\
Rural maximum & 183 & 183 \\
\hline
\end{tabular}

Table 11: Expected revenue per $\mathrm{kW}$ of DSR per HH service call participation for Business Case 3

\begin{tabular}{lll}
\hline & $\begin{array}{l}\text { Residential } \\
(\mathfrak{f} / \mathrm{kW} / \mathrm{year})\end{array}$ & $\begin{array}{l}\text { Commercial } \\
(\mathfrak{f} / \mathrm{kW} / \text { year })\end{array}$ \\
\hline Urban minimum & 0.7 & 1.1 \\
Urban mean & 2.2 & 3.7 \\
Urban maximum & 6.3 & 10.3 \\
Rural minimum & 1.1 & 1.8 \\
Rural mean & 4.5 & 7.4 \\
Rural maximum & 12 & 20 \\
\hline
\end{tabular}


Table 12 shows the expected annual revenues per end-user providing DSR based on their available flexible or full active demand and the average service call participation.

Table 12: Annual revenues per end-users providing DSR for Business Case 3

\begin{tabular}{lllll}
\hline & \multicolumn{2}{c}{ Residential } & \multicolumn{2}{c}{ Commercial } \\
& Typical & Full & Typical & Full \\
& $(£ /$ year $)$ & $(£ /$ year $)$ & $(£ /$ year $)$ & $(£ /$ year $)$ \\
& & & & \\
\hline Urban minimum & 3.8 & 9 & 73 & 234 \\
Urban mean & 13 & 30 & 236 & 763 \\
Urban maximum & 36 & 86 & 665 & 2148 \\
Rural minimum & 6 & 15 & 115 & 273 \\
Rural mean & 26 & 62 & 476 & 1538 \\
Rural maximum & 68 & 162 & 1257 & 4060 \\
\hline
\end{tabular}

As can be seen, the value of DSR in this business case can be deemed consistent with the value of DSR in the other distribution network business case (Business Case 2). This consistency suggests that the assessments are overall quite accurate, since both business cases somehow deal with distribution network reinforcement costs (Business Case 2 might involve investments in neighbouring networks and the network charges should reflect these investment costs).

It is important to note that the results in this section were calculated under the premise that the investment is needed immediately. As discussed in Section 4.5, in practice the reinforcement may be expected sometime in the future, and active demand may only defer the reinforcement if demand increases. In such cases, the results should be discounted based on the expected time when the reinforcement would be needed and the time that active demand can defer the reinforcement as expressed previously by (9). Examples of this discounting procedure for different times after which reinforcement would be needed and based on a typical 7\% discount rate and a 5\% peak reduction targets are presented in Table 13. 


\section{Table 13: Percentage of costs that can be averted with DSR.}

\begin{tabular}{ccccc}
\hline $\begin{array}{c}\text { Time to reinforcement } \\
\text { (years) }\end{array}$ & \multicolumn{4}{c}{ Annual peak demand growth } \\
$0 \%$ (avoidance) & $1 \%$ & $2 \%$ & $3 \%$ \\
\hline 0 & $100 \%$ & $29 \%$ & $16 \%$ & $11 \%$ \\
1 & $93 \%$ & $28 \%$ & $15 \%$ & $10 \%$ \\
3 & $81 \%$ & $24 \%$ & $13 \%$ & $9 \%$ \\
5 & $71 \%$ & $21 \%$ & $11 \%$ & $8 \%$ \\
7 & $62 \%$ & $18 \%$ & $10 \%$ & $7 \%$ \\
9 & $54 \%$ & $16 \%$ & $9 \%$ & $6 \%$ \\
\hline
\end{tabular}

From the results, it emerges how this application of capacity services is mainly attractive for networks that are close to their operational limits and, thus, will have to be reinforced in the near future. Load growth also plays an important role for this service, as DSR can defer investments for longer periods if load growth is low (e.g., $0 \%$ or $1 \%$ ).

\subsection{Discussion and policy implications}

The avoidance of transmission capacity charges (Business Case 1) provides the most modest results per end-user, with an average expected profit of $£ 7.50$ per year for residential end-users. Regardless, the service can be considered attractive due to its low call frequency (i.e., 15 calls per year).

The capacity services for DNOs (Business Case 2 and 3) prove to be case sensitive. Some applications would produce close to no value (e.g., networks that are far from their physical limits), whereas others could bring significant benefits, estimated in the order of $£ 200$ and $£ 4000$ per year for residential and small commercial end-users, respectively. The most attractive applications would likely be associated with high capacity charges and fixed costs, or networks approaching their operational limits and subject to significant demand growth uncertainty. These cases should be the main focus of business cases for aggregators and DSR providers to engage small active demand end-users. In addition, it is important to 
emphasize two points regarding these services. Firstly, the benefits presented correspond to the avoidance of immediate network reinforcements; these values have to be discounted for cases in which the reinforcement is expected in the future (i.e., using the coefficients in Table 7). Secondly, these benefits are associated with the average service frequency per end-user. If end-users were incentivised based on their participation, some of them could significantly increase their revenues by participating in all service calls (e.g., 106\% more for residential end-users); however, this would cause other end-users to participate less frequently and receive fewer benefits.

It is important to note that DSR providers and aggregators might use these services in combination with each other and possibly with other services, particularly as capacity service requirements may overlap (e.g., in the case a TRIAD and a DNO service call were to coincide at peak times for both the overall system and the local network). This may provide even stronger business case opportunities for DSR as more services emerge and their value is proven via proper quantification.

Finally, it is worth noting that, even though the proposed business cases for capacity services may offer high economic incentives and low call frequency, these benefits may not be properly internalised by existing policies and regulatory frameworks. In fact, there are two main issues with existing UK regulations that would have to be overcome to facilitate the proposed business cases. Firstly, the current distribution charging arrangements are not fully cost-reflective, thus encouraging DNOs to invest in traditional solutions (e.g., network reinforcements) without considering potential benefits from DSR. As a result, innovative distribution network solutions in the UK are only incentivised currently by government grants, such as the Low Carbon Networks fund (e.g., the Capacity to Customers project (ENWL, 2013)). Future regulations would have to devise cost-reflective incentives for small-customers (e.g., based on location, time of the day and other conditions), which should be as simple and transparent as for end-users to accept them. Secondly, current market arrangements isolate small end-users from the rest of the market to 
"protect" them from balancing responsibilities. This is not ideal for the proposed business cases that may offer significant benefits to end-users, but may also expose them to balancing responsibilities when providing DSR. Accordingly, new regulations would have to emerge to allow customers to benefit from DSR, without being “unfairly" exposed to penalties.

\section{CONClusion}

This paper discussed the need of proper quantification for DSR with the aim of identifying whether or not deploying DSR on a large scale that involves small commercial and residential end-users would make economic sense. More specifically, three DSR services based on the provision of "capacity" to the distribution and transmission networks were investigated. The services were chosen due to both their prospective low call frequency and potential high value, which make them particularly attractive with respect to energy services in current market conditions with relatively small price differentials. However, proper quantification of the potential to provide these capacity services was needed which would consider both the physical characteristics of active demand providing DSR and market aspects. Hence, comprehensive techno-economic models were developed and relevant numerical applications were assessed for realistic case studies relevant to the UK situation. The results show that the services consistently cause little disutility comfort to active demand end-users in most cases due to their low call frequency, with benefits that can be significant although tending to be case specific. In particular, benefits from DNO related services can vary from virtually zero to about $£ 200$ for the residential case (more than $£ 4000$ for the commercial case).

It was also discussed that the deployment of the proposed business cases for DSR from small endusers in the UK would require new policies and regulatory frameworks. These frameworks must properly 
internalise the benefits and costs associated with DSR, and guarantee that the interests of end-users are protected when facing balancing responsibilities associated with the DSR services.

Further research in progress aim at properly quantifying other DSR services, identifying the effects associated with DSR that may incentivise or deter the business model of other actors, and carrying out a comprehensive cost-benefit analysis that take into account the cost of enabling technologies (for instance, information and communication technologies) and the way that revenues may be shared among the different actors (for instance, aggregators and active demand end-users with different flexibility and availability characteristics).

\section{ACKNOWLEDGMENTS}

The authors wish to thank the European Commission for the partial economic support received to develop the research reported in this paper under the $7^{\text {th }}$ Framework Programme and the ADDRESS consortium as a whole. Mr Nicholas Good would also like to thank E.On New Build \& Technology Limited for funding his $\mathrm{PhD}$.

\section{REFERENCES}

Albadi, M.H., El-Saadany, E.F., 2008. A summary of demand response in electricity markets. Electrical Power System Research. 78, 1989-96.

Belhomme, R., Sebastian, M., Diop, A., Entem, M., Bouffard, F., et al., 2009. ADDRESS technical and commercial conceptual architectures. Available from: <http://www.addressfp7.org/config/files /ADD-WP1_Technical_and-Commercial_Architectures.pdf>.

Bradley, P., Leach, M., Torriti, J., 2013. A review of the costs and benefits of demand response for electricity in the UK. Energy Policy. 52, 312-27. 
Cossi, A.M., da Silva, L.G.W., Lázaro, R.A.R., Mantovani, J.R.S., 2012. Primary power distribution systems planning taking into account reliability, operation and expansion costs. IET Generation, Transmission \& Distribution. 6, 274-84.

Darby, S.J., McKenna, E., 2012. Social implications of residential demand response in cool temperate climates. Energy Policy. 49, 759-69.

De Ridder, F., Hommelberg, M., Peeters, E., 2011. Demand side integration: Four potential business cases and an analysis of the 2020 situation. European Transaction in Electric Power. 21,1902-13.

Dejvises, J., Mancarella, P., and Strbac, G., 2011. Thermo-electrical load modelling of buildings for assessment of demand response based on heating ventilation and air conditioning (HVAC) devices. Proceedings of the 21st International Conference on Electricity Distribution (CIRED), Frankfurt, pp. $1-4$.

Department of Energy \& Climate Change (DECC), 2013. Energy consumption in the UK. Available from: <https://www.gov.uk/government/collections/energy-consumption-in-the-uk>.

Doostizadeh, M., Ghasemi, H., 2012. A day-ahead electricity pricing model based on smart metering and demand-side management. Energy. 46, 221-30.

Electricity Northwest Limited (ENWL), 2013. About C2C: Key documents. Available from: <http://www.enwl.co.uk/c2c/about-c2c/key-documents>.

Elexon, 2013a. Imbalance pricing guidance: A guide to electricity imbalance pricing in Great Britain. Available from: <http://www.elexon.co.uk/wp-content/uploads/2013/11/imbalance_pricing_guidanc e_v5.0_cgi.pdf.

Elexon, 2013b. Load profiles and their use in electricity settlement. Available from: <http://www.elexon.co.uk/wp-content/uploads/2013/11/load_profiles_v2.0_cgi.pdf>.

Energy Networks Association (ENA), 2011. EHV distribution charging methodology (EDCM). Available from: <https://www.ofgem.gov.uk/ofgem-publications/44036/edcm-report-1april2011.pdf>. 
Flexitricity, 2010. Triad guidance notes. Available from: <http://www.flexitricity.com/docLibrary/3004102\%20Triad\%20guidance\%20notes\%202011\%201. 0.pdf〉.

GDF SUEZ, 2013. TRIADS. Available from: <http://www.gdfsuez-energy.co.uk/corporate/energysupply/customer-area/triads/>.

Giordano, V., Fulli, G., 2012. A business case for smart grid technologies: A systemic perspective. Energy Policy. 40, 252-9.

Gottwalt, S., Ketter, W., Block, C., Collins, J., Weinhardt, C., 2011. Demand side management—A simulation of household behavior under variable prices. Energy Policy. 39, 8163-74.

Green, J.P., Smith, S.A., Strbac, G., 1999. Evaluation of electricity distribution system design strategies. IEE Proceedings in Generation Transmission and Distribution. 146, 53-60.

Grenard, S., 2009. Optimal investment in distribution systems operating in a competitive environment. The University of Manchester, PhD thesis.

Gyamfi, S., Krumdieck, S., Urmee, T., 2013. Residential peak electricity demand response—Highlights of some behavioural issues. Renewable and Sustainable Energy Reviews. 25, 71-7.

Khodr, H.M., Vale, Z., Ramos, C., Faria, P., 2009. Optimization techniques for power distribution planning with uncertainties: A comparative study. Proceedings of the Power \& Energy Society General Meeting, pp. $1-8$.

Linares, P., 2013. Key economic factors influencing the adoption of the ADDRESS smart grid architecture. Available from: <http://www.addressfp7.org/config/files/ADD-WP5-T51-DEL-COMILLAS-D5.3KeyEconomicFactors.pdf>.

Mancarella, P., Chicco, G., 2013. Real-time demand response from energy shifting in distributed multigeneration. IEEE Transactions on Smart Grid. 4, 1928-38.

National Grid, 2013a. The statement of use of system charges. Available from: $<$ http://www2.nationalgrid.com/uk/Industry-information/System-charges/Electricity- 
transmission/Transmission-Network-Use-of-System-Charges/Statement-of-Use-of-SystemCharges/>.

National Grid, 2013b. Data explorer. Available from: <http://www2.nationalgrid.com/UK/Industryinformation/Electricity-transmission-operational-data/Data-Explorer/>.

Npower, 2013. TRIAD warning service. Available from: <http://www.npower.com/LargeBusiness/Buying-energy/Demand-Management/TriadWarningservice/index.htm>.

Ofgem, 2012. Promoting smarter energy markets. Available from: <https://www.ofgem.gov.uk/ofgempublications/42597/smarter-markets-strategy-consultation-document.pdf>.

Ofgem, 2013. Electricity demand profiles by sector. Available from: <https://www.ofgem.gov.uk/ofgempublications/57017/electricity-demand-profiles.xlsx>.

Ofgem, 2014b. Transition to smart meters. Available from: <https://www.ofgem.gov.uk/electricity/retailmarket/metering/transition-smart-meters>.

Ofgem, 2014a. Smarter Markets Programme. Available from: <https://www.ofgem.gov.uk/electricity/retailmarket/market-review-and-reform/smarter-markets-programme>.

Ofgem, 2014c. Charging arrangements. Available from: <https://www.ofgem.gov.uk/electricity/ distribution-networks/charging-arrangements>

Oren, S.S. 2013. A historical perspective and business model for load response aggregation based on priority service. Proceedings of the Hawaii International Conference on System Sciences. IEEE, pp. 2206-14.

Prüggler, N, 2013. Economic potential of demand response at household level-Are central-European market conditions sufficient?. Energy Policy. 60, 487-98.

Richardson, I., Thomson, M., Infield, D., Clifford, C., 2010. Domestic electricity use: A high-resolution energy demand model. Energy Buildings. 42, 1878-87. 
SINTEF Energy Research, 2003. Energy efficient and load curve impacts of commercial development in competitive markets phase 1 - basis for demand response. Available from: $<$ http://www.sintef.no/project/Efflocom/EFFLOCOM\%20report\%20no.\%201\%20Basis\%20for\%20 load\%20management\%5B1\%5D.pdf>.

Strbac, G., 2008. Demand side management: Benefits and challenges. Energy Policy. 36, 4419-26.

Strbac, G., Gan, C.K., Aunedi, M., Stanojevic, V., Djapic, P., Dejvises, J., 2010. Benefits of advanced smart metering for demand response based control of distribution networks control. Available from: $<$ http://www.energynetworks.org/modx/assets/files/electricity/futures/smart_meters /Smart_Metering_Benerfits_Summary_ENASEDGImperial_100409.pdf>.

Tan, Y.T., Kirschen, D., 2007. Classification of control for demand-side participation. Available from: $<$ http://www.ee.washington.edu/research/real/Library/Reports/Classification_of_DemandSide_Controls.pdf>.

Torriti, J., 2012. Price-based demand side management: Assessing the impacts of time-of-use tariffs on residential electricity demand and peak shifting in northern Italy. Energy. 44, 576-83.

Torriti, J., Hassan, M.G., Leach, M., 2010. Demand response experience in Europe: Policies, programmes and implementation. Energy. 35, 1575-83.

U.S. Department of Energy, 2013. Energy Plus. Available from: $<$ http://apps1.eere.energy.gov/buildings/energyplus/>. 